\title{
Design of Optimal Control Techniques For STATCOM Control Inputs in Power System
}

\author{
Sai Shankar, Yathisha L and K T Veeramanju
}

\begin{abstract}
The selection of Static Synchronous Compensator (STATCOM) control input along with the appropriate optimized feedback controller is an current challenge in the present scenario of power system network. Hence, in this paper the optimal control techniques are proposed for the STATCOM phillips heffron model in various combinations such as individual, coordinated and switching between individual control inputs. The simulation results of all the proposed optimal control approaches are compared for the slection of best optimal control approach of the STATCOM model to damp the oscillations in power sytem.
\end{abstract}

Index Terms - LQR, Switching Control, STATCOM \& Power System.

\section{INTRODUCTION}

Latest development of power electronics has introduced Flexible AC Transmission Systems (FACTS) controllers to damp the oscillations, enhance power system stability, etc in power system. The STATCOM is family of FACTS device connected in shunt type as shown in Figure 1. The primary function of STATCOM is to support bus voltage by injecting or observing reactive power. In addition to the primary function STATCOM also improves the power system stability by damping oscillations.

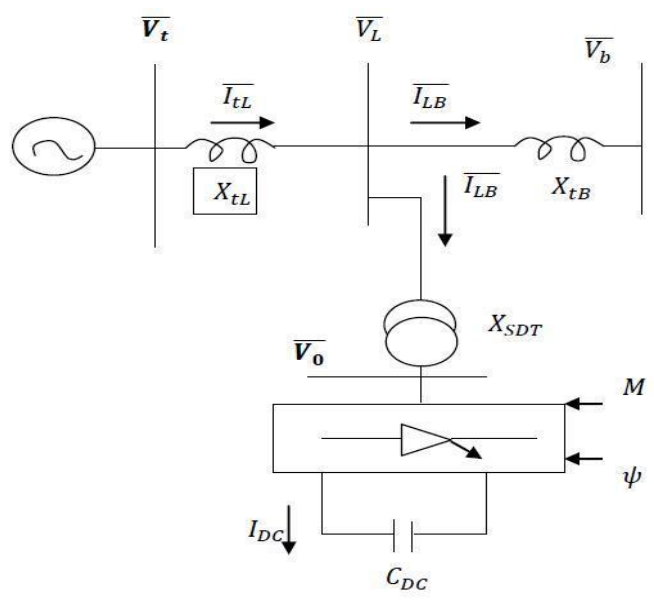

Figure 1: STATCOM connected to SMIB in power system

Manuscript revised June 9, 2019 and published on July 10, 2019

Sai Shankar, PhD scholar, Electrical Engineering, Visvesvaraya Technological University, India

Yathisha L, Associate Professor, Electronics \& Communication Engineering, ATME College of Engineering, Mysore, India.

K $\boldsymbol{T}$ Veeramanju, Professor in Sri Jayachamarajendra College of Engineering (SJCE), Mysore, India.
(Mohammad Reza Safari Tirtashi \& Ahmad Rohani et al. 2010) proposed fuzzy logic controller for Power System Stabilizer (PSS) \& STATCOM FACTS device for three operating conditions (light, nominal \& heavy loads) in power sytem. The simulation results provides good dynamic damping characteristics over wide ranges of operating condition. To increase the transient stability in power sytem (V Rajkumar \& Srihari Dattabhimaraju P et al.2013) introduced Artificial Neural Network (ANN) controller for the STATCOM SMIB model and the results indicates that the proposed control provides better damping of oscillations.

(Sangram Keshori Mohapatra \& Nanda Kishore Ray et al. 2012) for the improvement of power system stability investigated the optimization technique using Differential Evaluation (DE) algorithm for the STATCOM based damping controller in power system. The remote and local signals are applied for the system to evaluate the proposed controller and the results revael that the remote signal with time delay is better compared to local signal.

(Sangram Keshori Mohapatra \& Sidhartha Panda et al.2013) presents the power system stability improvemnt using STATCOM based damping controller. The performance of the proposed controller is evaluated under different disturbances for both single-machine infinite bus power system and multimachine power system. State feedback control approach to the single infinite bus machine and multimachine systems is proposed by (A.U. Lawan et al. 2014) and the effectiveness of the proposed control method is compared themselves by applying various disturbances. (M Chandanpraneeth \& G Manohar et al. 2018) presents an novel approach to determine the controller parameters of Prportional Integral Derivative (PID) control and Fuzzy Logic design. The simulation results reveal that the proposed controllers obtain high quality solution with good computation efficiency.

(Morteza Haghshenas \& Mohammad Hajibabaee at al. 2016) introduced modified shuffled frog leaping algorithm (MSFLA) for optimal selection of STATCOM damping controller parameters, in order to shift the closed loop eigenvalues toward the desired stability region. The experiment is performed for SMIB and the simulation results shows the better performance compared to conventional control techniques. The coordinated control of automatic voltage regulator of synchronous generator and static synchronous compensator in multi-machine power systems is introduced by (Bangjun Lei \& Shumin Fei et al. 2014) and pseudo-generalized Hamiltonian theory is used to design the controllers of STATCOM and AVR coordinately. The simulation results indicates the better performance compared to earlier conventional control techniques. 
Switched systems are combination of group of sub systems combined to form a new property of system, which is not present in any of the subsystems. (Zhi Hong Huang \& Cheng Xiang et al. 2007) investigated the necessary and sufficient conditions for stability of arbitrary switched second order linear time invariant (LTI) systems. Performance based switching algorithm for LTI systems based on Lyapunov stability criteria was developed by (Lalitha et al. 2005 \& 2006). Switching control strategy was proposed for the UPFC, based on three scenarios involving high, low and normal load conditions by (Yathisha L et al. 2017).

In summary, a single optimized control input of STATCOM will not be suitable over entire dynamic range of applications of today's complex power system.

Hence, in the present work, Optimal Linear Quadratic Regulator (LQR) feedback control techniques are applied for STATCOM control inputs Deviation in Pulse Wodth Modulation Index $(\Delta C) \&$ Deviation in Phase Angle $\Delta \psi)$ of shunt inverters in various combinations such as individually, coordinated \& switching between individual control inputs. The proposed optimal control techniques are simulated using MATLAB/SIMULINK @ platform. Finally, the results are compared with respect to optimization (performace index $J=\int_{0}^{\infty} y^{2} d t$ ), peak overshoots \& settling time to draw the relevant conclusion.

The remainder of the paper is organized as follows. Section 2 describes Linear Time Invariant (LTI) model of power system istalled with STATCOM. Optimal control theory, switched linear control theory and Experimental cases are respectively discussed in Sections 3 and 4 . Simulation results and discussions are presented in Section 5. Section 6 concludes the paper.

\section{Dynamic Model of Power System installed with STATCOM}

The linearised Phillips-Heffron model of a power system installed with a static synchronous compensator (STATCOM) demonstrates the application of the state space model in analysing the damping effect of the STATCOM and designing a STATCOM stabilizer to improve power system oscillation stability. follows:

Its state space formulation can be expressed as

$$
\begin{gathered}
\dot{x}(t)=A x(t)+B u(t) \\
x(t)=\left[\begin{array}{llll}
\Delta \delta & \Delta \omega & \Delta E_{q}^{\prime} & \Delta E_{f d}
\end{array}\right] \\
u(t)=\left[\begin{array}{ll}
\Delta C & \Delta \psi
\end{array}\right]
\end{gathered}
$$

$$
\begin{gathered}
A=\left[\begin{array}{cccc}
0 & \omega_{o} & 0 & 0 \\
-\frac{k_{1}}{M} & -\frac{D}{M} & -\frac{k_{2}}{M} & 0 \\
-\frac{k_{1}}{T^{\prime} d o} & 0 & -\frac{k_{3}}{T^{\prime} d o} & \frac{1}{T^{\prime} d o} \\
-\frac{k_{A} k_{5}}{T_{A}} & 0 & -\frac{k_{A} k_{6}}{T_{A}} & \frac{1}{T_{A}}
\end{array}\right] \\
B=\left[\begin{array}{cc}
0 & 0 \\
-\frac{k_{p c}}{M} & -\frac{k_{p \Psi}}{M} \\
-\frac{k_{q c}}{T_{d o}^{\prime}} & -\frac{k_{q \Psi}}{T_{d o}^{\prime}} \\
-\frac{k_{A} k_{v c}}{T_{A}} & -\frac{k_{A} k_{v \Psi}}{T_{A}}
\end{array}\right]
\end{gathered}
$$

Where, the state variables are the rotor angle deviation $(\Delta \delta)$, rotor speed deviation $(\Delta \omega)$, q-axis component deviation $\left(\Delta E_{q}^{\prime}\right)$ and field voltage deviation $\left(\Delta E_{f d}\right)$.

\section{OPTIMAL CONTROL THEORY}

Finding the controller gain $K$ by optimizing the control and output energy is defined as optimal control. The most popular optimal control theory is Linear Quadratic Regulator (LQR) Algorithm and this tool is used for the current research to find the controller gains for the STATCOM connected power system model. A brief expalanation of LQR is as follows (Yathisha L and S Patil Kulkarni et al. 2013; Yathisha L and S Patil Kulkarni et al. 2015; Yathisha L and S Patil Kulkarni et al. 2017):

The Linear time invariant system is given by,

$$
\begin{aligned}
& \dot{x}(t)=A x(t)+B u(t) \\
& y(t)=C x(t)
\end{aligned}
$$

The closed loop system with negative feedback is represented by,

$$
\dot{x}(t)=(A-B K) x(t)
$$

The performance index $J$ which is given by,

$0, R \geq 0$

$$
J(x, u, Q, R)=\int_{0}^{\infty}\left(x^{T} Q x+u^{T} R u\right) d t, \quad Q \geq
$$

The aim of the LQR problem is to design a control law $u=-K x$ by minimizing the objective function $J$ with the solution given by,

$$
K=-R^{-1} B^{T} P
$$


Thus the control law as

$$
u(t)=-K x(t)=-R^{-1} B^{T} P
$$
equation:

In which $P$ must satisfy the reduced Riccati

$$
P A+A^{T} P-P B R^{-1} B^{T} P+Q=0
$$

By using the MATLAB command lqr the algebraic riccatti equation is computed.

$$
[K, P, E]=\operatorname{lqr}(A, B, Q, R)
$$

\section{SWITCHING CONTROL TECHNIQUES}

Switched systems are a class of Hybrid Systems (HS) which consist of several subsystems that switch according to a given switching law. Fig. 2, shows the general switched linear systems.

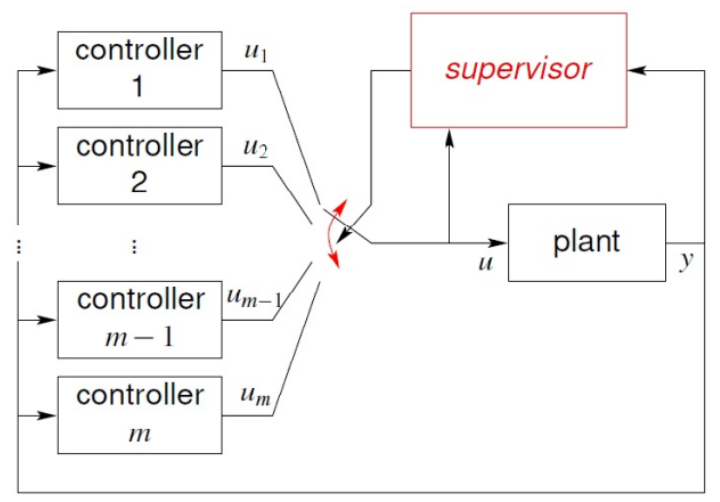

Figure 2: General Switched Linear Systems

\section{A. Advantages of Switching Control:}

- Switching between two feedback control structure is to select the best control structure for the particular application.

- If any of the component failure in one of the control structure, the switching supervisor will take care of the same and alternate control will be in place.

- Switching between two control inputs will combine the properties of both control structures and results in new control structure which will not present in any of the two individual control structures.

A switched-linear system model for the current research is as follows:

$$
\dot{x}=A_{\sigma} x(t)
$$

The switching signal $\sigma(t)$ indicates

$$
\begin{aligned}
& \dot{x}(t)=A_{\alpha} x(t)=i f, \quad \sigma=\alpha \\
& =A_{\beta} x(t)=i f, \quad \sigma=\beta
\end{aligned}
$$

Where,

$$
\begin{aligned}
& A_{\alpha}=A-B K_{\alpha} \\
& A_{\beta}=A-B K_{\beta}
\end{aligned}
$$

and

$$
\begin{aligned}
& A_{\alpha}=A-B_{1} K_{1} \\
& A_{\beta}=A-B_{2} K_{2}
\end{aligned}
$$

Here, $B_{1}=\Delta C \& B_{2}=\Delta \psi$ and the feedback controllers $K_{1} \& K_{2}$ are derived from the optimal LQR control theory by tuning the weighting matrices.

\section{B. Switching Control Algorithm:}

The existing switching algorithm by (Lalitha $\mathrm{S}$ Devarakond et al. 2006; Yathisha L et al. 2018) is as follows:

- Define the two closed loop systems $A_{\alpha} \& A_{\beta}$.

- Determine $T_{0}$ by solving the algebraic Lyapunov Equation:

$$
A_{\alpha}^{T} T_{0}+T_{0} A_{\alpha}=-C^{T} C
$$

- Using, $A_{2}$ define the switching matrix:

$$
S=-\left(A_{\beta}^{T} T_{0}+T_{0} A_{\beta}+C^{T} C\right)
$$

- Now, the switching rule is,

$$
\begin{gathered}
\sigma=\beta \quad \text { if } \prec x, S x>>0 \\
=\alpha \quad \text { otherwise }
\end{gathered}
$$

\section{EXPERIMENTAL SET-UP}

The numerical values of the $A \& B$ matrices of the system considered for the experiment (Sai Shanksr \& Yathisha L et al. 2018) is as follows:

$$
A=\left[\begin{array}{llll}
0 & 377 & 0 & 0 \\
-0.07076 & 0 & -0.0214 & 0 \\
-0.08322 & 0 & -0.4873 & 0.1982 \\
1513 & 0 & -3516 & -100
\end{array}\right]
$$

$$
B=\left[\begin{array}{ll}
B_{1} & B_{2}
\end{array}\right]=\left[\begin{array}{ll}
0 & 0 \\
-0.0474 & -0.1492 \\
-0.2305 & 7.53 * 1.0 e-03 \\
4591 & -311
\end{array}\right.
$$

The proposed optimal LQR control techniques for the two STATCOM control inputs $(\Delta C \& \Delta \psi)$ are experimented by considering the following cases:

Case I.(i): Optimal LQR feedback contrgbfer $K_{1}$ is designed for the control input $B_{1}$. 


$$
K_{1}=\left[\begin{array}{llll}
1.1660 & -48.5170 & 0.6684 & 0.9781
\end{array}\right]
$$

Case I.(ii): Optimal LQR feedback controller $K_{2}$ is designed for the control input $B_{2}$.

$$
K_{2}=\left[\begin{array}{llll}
-2.9311 & -101.3622 & 5.9240 & -0.6932
\end{array}\right]
$$

Case I.(iii): Optimal switching control technique is proposed for the control input $B_{1}$. The controller gains $K_{\alpha} \&$ $K_{\beta}$ are defined by tuning the weighting matrices. The switching matrices $(S)$ for the state variables $\Delta \delta \& \Delta \omega$ along with $K_{\alpha} \& K_{\beta}$ are give by,

$$
\begin{gathered}
K_{\alpha}=K_{1}=\left[\begin{array}{llll}
1.1660 & -48.5170 & 0.6684 & 0.9781
\end{array}\right] \\
K_{\beta}=\left[\begin{array}{llll}
8.3834 & -445.7761 & 11.3494 & 9.9743
\end{array}\right]
\end{gathered}
$$

$$
S(\Delta \delta)=\left[\begin{array}{llll}
0.0005 & -0.0325 & 0.0008 & 0.0003 \\
-0.0325 & 1.9192 & -0.048 & -0.021 \\
0.0008 & -0.0488 & 0.0012 & 0.0005 \\
0.0003 & -0.0217 & 0.0005 & -0.000
\end{array}\right] \times 10^{4}
$$$$
S(\Delta \omega)=\left[\begin{array}{llll}
0.0008 & -0.0463 & 0.0011 & 0.0005 \\
-0.0463 & 2.5618 & -0.0600 & -0.0290 \\
0.0011 & -0.0600 & 0.0014 & 0.0006 \\
0.0005 & -0.0290 & 0.0006 & -0.000
\end{array}\right]
$$

Case I.(iv): Optimal switching control technique is proposed for the control input $B_{2}$. The controller gains $K_{\alpha} \&$ $K_{\beta}$ are defined by tuning the weighting matrices. The switching matrices $(S)$ for the state variables $\Delta \delta \& \Delta \omega$ along with $K_{\alpha} \& K_{\beta}$ are give by,

$$
\begin{gathered}
K_{\alpha}=K_{2}=\left[\begin{array}{llll}
-2.9311 & -101.3622 & 5.9240 & -0.6932
\end{array}\right] \\
K_{\beta}=\left[\begin{array}{llll}
-2.7061 & -257.1075 & -2.1811 & -9.5649
\end{array}\right]
\end{gathered}
$$$$
S(\Delta \delta)=\left[\begin{array}{llll}
-0.0192 & 6.0410 & 0.2286 & 0.3814 \\
6.0410 & 848.4701 & 103.5166 & 24.2306 \\
0.2286 & 103.5166 & 8.4763 & 4.6630 \\
0.3814 & 24.2306 & 4.6630 & -0.0094
\end{array}\right]
$$$$
S(\Delta \omega)=\left[\begin{array}{llll}
0.0000 & -0.0079 & -0.0004 & -0.0004 \\
-0.0079 & 1.4318 & 0.0538 & 0.0408 \\
-0.0004 & 0.0538 & 0.0017 & 0.0009 \\
-0.0004 & 0.0408 & 0.0009 & -0.0000
\end{array}\right]
$$

Case II: Optimal LQR feedback controller $K_{a}$ is designed for the coordinated control input $B_{a}=\left[\begin{array}{ll}B_{1} & B_{2}\end{array}\right]$.

$$
K_{a}=\left[\begin{array}{cccc}
0.2626 & -4.9449 & -0.4788 & 0.9762 \\
-0.7554 & -60.2200 & 0.4611 & -0.0666
\end{array}\right]
$$

Case III: Switching Between the two STATCOM control inputs $B_{1}(\Delta C) / B_{2}(\Delta \psi)$ are considered for this case.

\begin{tabular}{|c|c|}
\hline$B=\left[\begin{array}{ll}B_{1} & B_{2}\end{array}\right]$ & $K_{1} / K_{2}$ \\
\hline$B=\left[B_{1}\right]$ & $K_{1}^{\prime}=\left[\begin{array}{c}K_{11} \\
0\end{array}\right.$ \\
\hline$B=\left[B_{2}\right]$ & $K_{2}^{\prime}=\left[\begin{array}{c}0 \\
K_{21}\end{array}\right.$ \\
\hline
\end{tabular}

The switching matrices $(S)$ for the current case is as below,

$$
S(\Delta \delta)=\left[\begin{array}{llll}
0.0000 & 0.0666 & -0.0002 & 0.0000 \\
0.0666 & 4.5181 & -0.1394 & 0.0158 \\
-0.0002 & -0.1394 & 0.0008 & -0.0001 \\
0.0000 & 0.0158 & -0.0001 & 0.0000
\end{array}\right]
$$

$$
\mathrm{S}(\Delta \omega)=\left[\begin{array}{llll}
-0.0009 & 0.9519 & -0.0016 & -0.0001 \\
0.9519 & 66.0059 & -2.0116 & 0.2302 \\
-0.0016 & -2.0116 & 0.0091 & -0.0006 \\
-0.0001 & 0.2302 & -0.0006 & 0.0000
\end{array}\right]
$$

In order for $K_{1} \& K_{2}$ corresponding to their $B_{1} \&$ $B_{2}$ they are modified and defined are shown in Table I.

Table 1: Modified controller gains for switching

\section{SIMULATION RESULTS}

The simulations are carried for all the proposed three cases to compare the results to select the best approach of control technique in future for the sate variables rotor angle \& rotor speed deviations. Fig's 3-4, shows the responses of rotor angle deviation $(\Delta \delta) \&$ rotor speed deviation $(\Delta \omega)$ state variables for the Case I (i), Case I (ii), Case II \& Case III. Case I (iii) \& Case I (iv) responses of state variables $\Delta \delta \& \Delta \omega$ are shown from Fig's 5-8. The optimization (performance index $J=\int_{0}^{\infty} y^{2} d t$ ) is tabulated for all the cases and depicted in tables II-IV.

The results of Case I (i), Case I (ii), Case II \& Case III (Fig's 3-4) and Tables II, reveal that for the state variable rotor angle deviation $(\Delta \delta)$ the coordinated design of two STATCOM control inputs $\left(B_{1}+B_{2}\right)$ of case II, along with the optimal LQR control provides better performance compared to other cases of individual control inputs as well as switching between two control inputs. For, the rotor speed deviation $(\Delta \omega)$ the switching between two STATCOM control inputs (Switch $B_{1} / B_{2}$ ) provides good damping as well as better optimization compared to all other cases.

The simulation results depicted in Fig's 5-7 (Case I (iii) \& Case I (iv)) for the two STATCOM control inputs, indicates for the first state variable $\Delta \delta$ switching between two optimal LQR feedback controllers will select the better individual feedback controller and for the second state variable $\Delta \omega$ switching between two feedback controllers shows improved performance in damping as well as optimization compared to using individual feedback control structures for both the STATCOM control inputs $\left(B_{1} \& B_{2}\right)$. 
Available online at www.ijrat.org

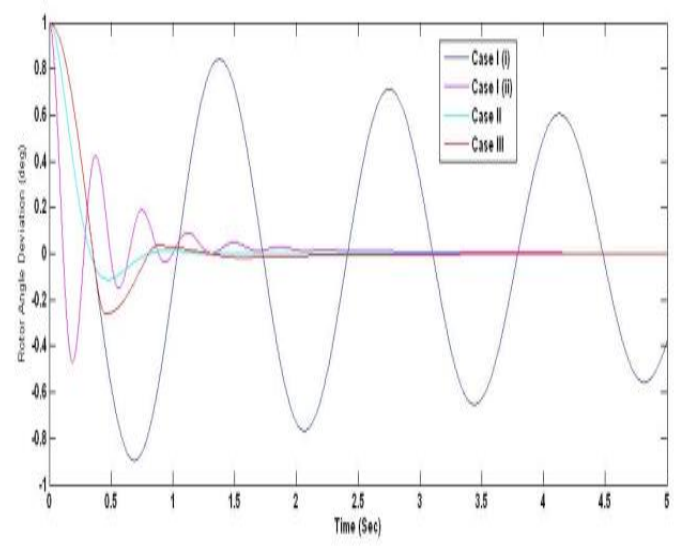

Figure 3: Rotor Angle Deviation Responses

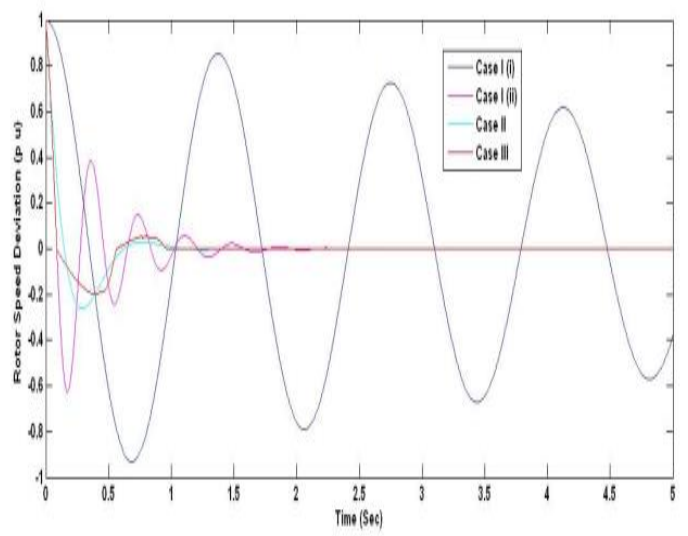

Figure 4: Rotor Speed

Deviation Responses

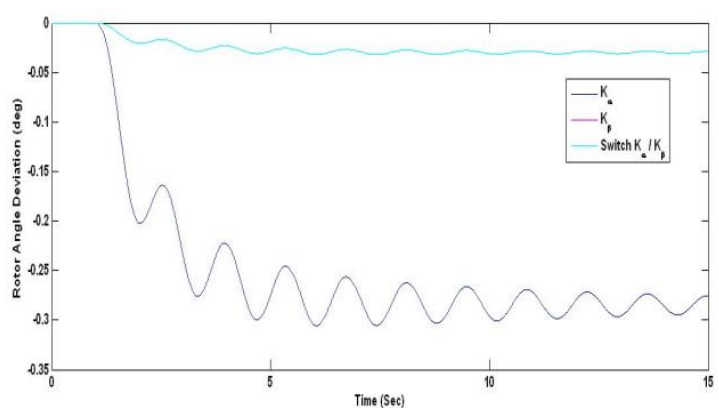

Figure 5: Rotor Angle Deviation Responses for Case III Control Input $B_{1}$

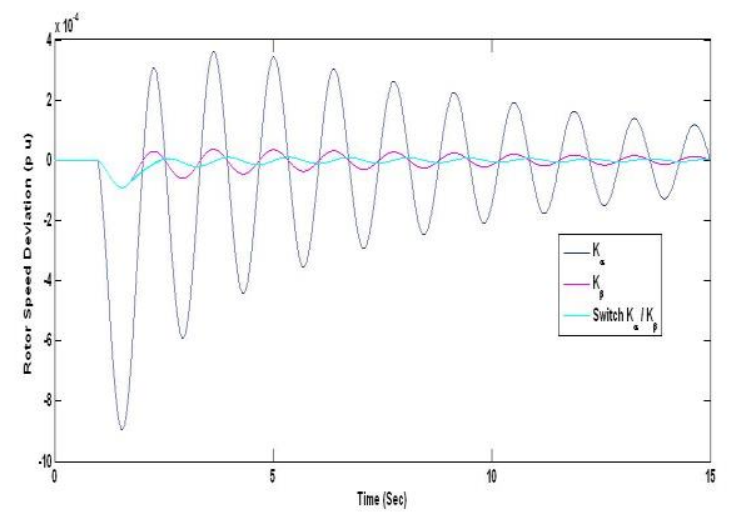

Figure 6: Rotor Speed Deviation Responses for Case III Control Input $B_{1}$

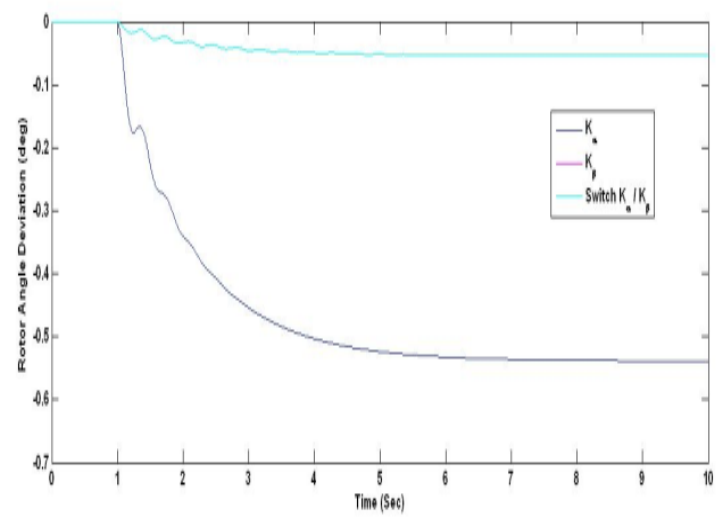

Figure 7: Rotor Angle Deviation Responses for Case III Control Input $B_{2}$

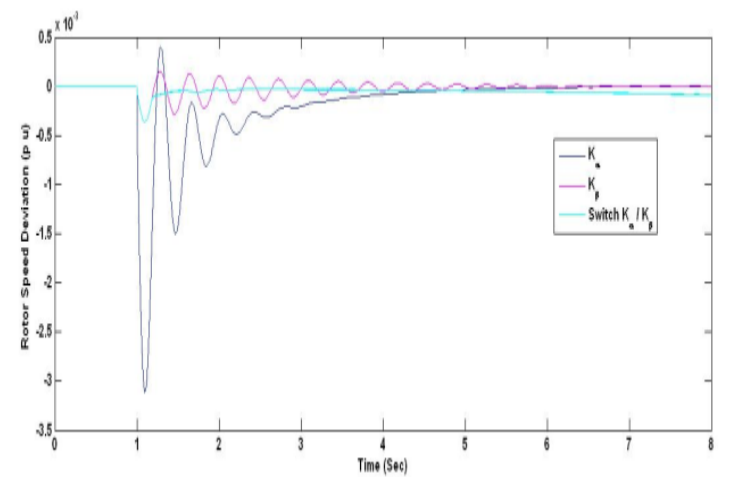

Figure 8: Rotor Speed Deviation Responses for Case III Control Input $B_{2}$ 
Table 2: Comparison of performance index $\left(J=\int_{0}^{\infty} y^{2} d t\right)$

\begin{tabular}{|c|c|c|}
\hline Cases & $\Delta \delta$ & $\Delta \omega$ \\
\hline Case I (i) & 1.437 & 1.506 \\
\hline Case I (ii) & 0.09738 & 0.09293 \\
\hline Case II & 0.1259 & 0.05442 \\
\hline Case III & 0.191 & 0.04434 \\
\hline
\end{tabular}

Table 3: Comparison of performance index $\left(J=\int_{0}^{\infty} y^{2} d t\right)$ for Case I (iii)

\begin{tabular}{|c|c|c|}
\hline Controller & $\Delta \delta$ & $\Delta \omega$ \\
\hline$K_{\alpha}$ & 0.9865 & $9.199 \times 10^{-7}$ \\
\hline$K_{\beta}$ & 0.0108 & $9.662 \times 10^{-9}$ \\
\hline Switch $K_{\alpha} / K_{\beta}$ & 0.0108 & $4.805 \times 10^{-9}$ \\
\hline
\end{tabular}

Table 4: Comparison of performance index $\left(J=\int_{0}^{\infty} y^{2} d t\right)$ for Case I (iv)

\begin{tabular}{|c|c|c|}
\hline Controller & $\Delta \delta$ & $\Delta \omega$ \\
\hline$K_{\alpha}$ & 1.568 & $1.678 \times 10^{-6}$ \\
\hline$K_{\beta}$ & 0.01537 & $4.214 \times 10^{-8}$ \\
\hline Switch $K_{\alpha} / K_{\beta}$ & 0.01537 & $3.254 \times 10^{-8}$ \\
\hline
\end{tabular}

\section{CONCLUSION}

In today's complicated power system network, the use of single controller or single STATCOM control input is not sufficient to reduce the peak overshoots and damping oscillations. Hence, in this paper the two STATCOM control inputs are effectively utilized in various combinations such as individual, coordinated and switching between two STATCOM control inputs. The feedback controllers are derived for each case using optimal LQR control techniques. The simulation results of all the various combinations concludes that for the state variable rotor angle deviation $(\Delta \delta)$ the coordinated control design of STATCOM control inputs $\Delta C+\Delta \psi$ provides good damping and for the state variable rotor speed deviation the switching between two STATCOM control inputs $\Delta C \Delta \psi$ provides better damping compared to all other approaches various control approaches.

\section{REFERENCES}

[1] Mohammad Reza Safari Tirtashi, Ahmad Rohani and Reza Noroozian, "PSS and STATCOM Controller Design for Damping Power System Oscillations Using Fuzzy Control Strategies", Proceedings of 18th Iranian Conference on Electrical Engieering, IEEE Xplore, 11th to 13th May 2010, pp. 901-906.

[2] V Rajkumar and Srihari Dattabhimaraju, "ANN Controlled STATCOM for Improving Transient Stability of the Power System", International Journal of Engineering Research \& Technology (IJERT), Vol. 2 Issue 2, February 2013, pp. 1-5, ISSN: 2278-0181.

[3] Sangram Keshori Mohapatra, Nanda Kishore Ray and Subrunsu Kulia, "Power System Stability Improvements Using Differential Evaluation Algorithm Based Controller for STATCOM", International Journal of Scientific and Research Publications, Volume 2, Issue 12, December 2012, pp. 1-6, ISSN 2250-3153.

[4] Sangram Keshori Mohapatra, Sidhartha Panda and Prasant Kumar Satpathy, "STATCOM based Damping Controller in Power Systems for Enhance the Power System Stability", World Academy of Science, Engineering and Technology International Journal of Electrical and Computer Engineering Vol 7, No 2, 2013, pp. 174-183.

[5] A.U. Lawan, "State Feedback Approaches for Designing A Statcom Supplementary Controller for Oscillations Damping", The International Journal Of Engineering And Science (IJES), Volume 3,
Issue 7, pp. 27-37, 2014, ISSN : 2319- 1813.

[6] Mukku Chandanpraneeth and Dr. T. Gowri Manohar, "Design and Analysis of Fuzzy \& GA-PID Controllers for Optimized Performance of STATCOM", International Research Journal of Engineering and Technology (IRJET), Vol. 5, Issue 8, Aug 2018, pp. 1539- 1545.

[7] Morteza Haghshenas, Mohammad Hajibabaee and Mahmoud Ebadian, "Controller Design of STATCOM Using Modified Shuffled Frog Leaping Algorithm for Damping of Power System Low Frequency Oscillations", International Journal of Mechatronics, Electrical and Computer Technology (IJMEC), Vol. 16, Issue 19, Jan 2016, pp. 2786-2799.

[8] Bangjun Lei, Shumin Fei and Junyong Zhai, "Coordinated control of static synchronous compensator and automatic voltage regulator in multi-machine power systems using pseudo-generalized Hamiltonian theory", Journal of Systems and Control Engineering, Institution of Mechanical Engineers, Vol. 228, Issue 3, pp. 154-166.

[9] Z H Huang and C Xiang, " A necessary and sufficient condition for stability of arbitrarily switched second-order LTI System: Marginally stable case", Proceedings of the 22nd IEEE International Symposium on Intelligent Control, Part of IEEE Multiconference on Systems and Control, Singapore: IEEE, 2007. pp. 83-88.

[10] Lalitha S. Devarakonda "Performance Based Switching Control for Single Input LTI Systems", M.S. Thesis, Department of Electrical Engineering, Graduate Faculty of the Louisiana State University and Agricultural and Mechanical College Dec 2005.

[11] Jorge L. Aravena and Lalitha Devarakonda, "Performance Driven Switching Control", IEEE Transactions on Industrial Electronics, 2006, July 9-12, 2006, pp. 31-36.

[12] Yathisha L, Kourosh Davoodi and S Patil Kulkarni "Optimal switching control strategy for UPFC for wide range of operating conditions in power system", 3rd Indian Control Conference, IEEE Xplore, Jan 2017, Indian Institute of Technology (IIT), Guwhati, pp 225-232. DOI:10.1109/INDIANCC.2017.7846479.

[13] Yathisha L and S Patil Kulkarni "Optimum LQR Switching Approach for the Improvement of STATCOM Performance", Springer LNEE, Vol 150, E-ISSN: 1876-1100, 2013, pp. 259-266, DOI 10.1007/978-1-4614-3363-7_28.

[14] Yathisha L and S Patil Kulkarni "Application and comparison of switching control algorithms for power system stabilizer", IEEE International Conference on Industrial Instrumentation and Control (ICIC), IEEE Xplore, May 2015, Pune, pp 1300-1305. DOI:10.1109/IIC.2015.7150949.

\section{AUTHORS PROFILE}

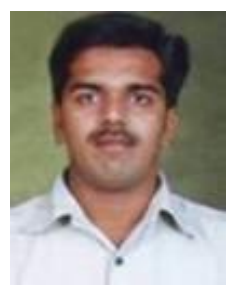

Sai Shankar received his Masters Degree in VLSI Design and Embedded Systems from SJCE, Visvesvaraya Technological University in the year 2013. Presently he is working towards Doctoral Degree in Electrical Engineering, in the field of control systems in the prestigious Visvesvaraya Technological University, India. He has been worked as an Asst Professor in GSSS Institute of Engineering and Technology Mysore, since 2005 to 2017. His areas of interests are Power Systems, Control Systems and Hybrid Control Systems.

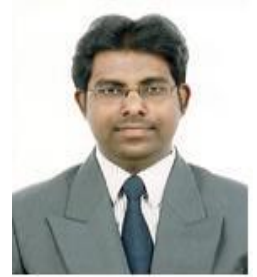

Yathisha L. received his Doctoral Degree in Control Systems \& Master's Degree in Industrial Electronics from SJCE, Visvesvaraya Technological University (VTU) in the year 2017 \& 2010 respectively. Since 2012 he is working as an Associate Professor in the Department of Electronics \& Communication Engineering, ATME College of Engineering, Mysore, India. His areas of interests are Control Systems, Power Systems and Hybrid Control Systems. e-mail: yathisha.171@gmail.com 
International Journal of Research in Advent Technology, Vol.7, No.6, June 2019

E-ISSN: 2321-9637

Available online at www.ijrat.org

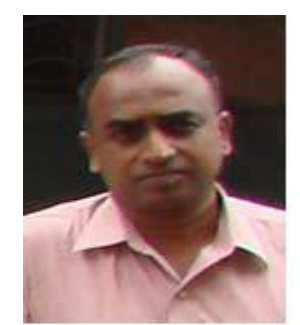

K T Veeramanju recieved his Master's Degree from Indian Institute of Science (IISC), Bangalore in the year 1992 and Obtained Ph.D. degree from Kuvempu University in the year 2007. $\mathrm{He}$ is currently a Professor in Sri Jayachamarajendra College of Engineering (SJCE), Mysore. His research interests includes Power Systems, Control Systems, Hybrid \& Stochastic control systems. 